\title{
Fatigue Performance of Heat Treated TC21 Ti-Alloy
}

\author{
Ramadan N. Elshaer ${ }^{1}$, Khaled M. Ibrahim², Azza F. Barakat ${ }^{3}$, Reham R. Abbas ${ }^{4}$ \\ ${ }^{1}$ Tabbin Institute for Metallurgical Studies, Cairo, Egypt \\ ${ }^{2}$ Central Metallurgical R \& D Institute, Cairo, Egypt \\ ${ }^{3}$ Faculty of Engineering, Helwan University, Cairo, Egypt \\ ${ }^{4}$ Faculty of Engineering, Suez University, Suez, Egypt \\ Email: ramadan_elshaer@yahoo.com
}

How to cite this paper: Elshaer, R.N., Ibrahim, K.M., Barakat, A.F. and Abbas, R.R. (2019) Fatigue Performance of Heat Treated TC21 Ti-Alloy. Open Journal of Metal, 9, 11-18.

https://doi.org/10.4236/ojmetal.2019.92002

Received: March 14, 2019

Accepted: June 27, 2019

Published: June 30, 2019

Copyright (c) 2019 by author(s) and Scientific Research Publishing Inc. This work is licensed under the Creative Commons Attribution International License (CC BY 4.0).

http://creativecommons.org/licenses/by/4.0/

(c) (i) Open Access

\begin{abstract}
TC21 is considered a new titanium alloy that is used in aircraft applications as a replacement for the famous Ti-6Al-4V alloy due to its high strength. The effect of single and duplex stage heat treatments on fatigue behavior of TC21 Ti-alloy (Ti-6Al-2Sn-2Zr-3Mo-1Cr-2Nb-0.09Si, wt.\%) was investigated. Two heat treatment cycles were applied on as-received TC21 Ti-alloy. The first cycle was called single stage heat treatment (SSHT). The other cycle was named duplex stage heat treatment (DSHT). Typical microstructures of SSHT $\&$ DSHT composed of primary equiaxed $\alpha$ phase, residual $\beta$ phase and secondary $\alpha$ phase $\left(\alpha_{\mathrm{s}}\right)$. Secondary $\alpha$ phase was precipitated in the residual $\beta$ phase due to low cooling rate using air cooling and aging treatment. Morphology of $\alpha$ phase does not change after solution treatments, while their volume fraction and grain size were changed. SSHT showed the highest fatigue strength of $868 \mathrm{MPa}$ due to high tensile strength, hardness and existing of high percentages of residual $\beta$ phase in the microstructure. However, DSHT reported lower fatigue strength of $743 \mathrm{MPa}$ due to increasing grain size of $\alpha$ phase. The fracture surface of fatigue samples showed cleavage ductile fracture mode for both heat treatment cycles.
\end{abstract}

\section{Keywords}

TC21 Ti-Alloy, Solution Treatment, Microstructure, Hardness, Tensile, Fatigue

\section{Introduction}

Titanium alloys, especially $\alpha+\beta$ titanium alloys, are widely used in advanced aerospace applications, aero-engines and chemical industries. The combination 
of high strength-to-weight ratio, good fatigue performance and excellent corrosion resistance makes them the best material choices for some critical applications [1] [2] [3]. Titanium alloys have become one of the indispensable structure materials for airplanes. They are used in advanced airplanes up to $30 \%-50 \%$ weight of the total structure, for instance, $41 \%$ in F-22 fighters [4]. TC21 (Ti-6Al-2Sn-2Zr-3Mo-1Cr-2Nb-Si, wt.\%) alloy is a new category of $\alpha+\beta$ titanium alloys with high strength, toughness, damage-tolerance properties and low crack propagation rate and provides weight reduction, long service life, and high reliability in fabricated aircraft structural components such as frames and beams [2] [5]. By applying a heat treatment technique, TC21 alloy can obtain a better combination of tensile properties, fracture toughness, and low fatigue crack growth rate. In such a case, the performance and engineering application value of TC21 Ti-alloy will be better than the widely used conventional Ti6Al4V alloy [6].

Wu et al. [7] reported that Ti-6Al-4V microstructures had considerable effects on high cycle fatigue strength and usually it decreased in the order of bimodal, lamellar and equiaxed microstructure. Davari et al. [8] reported that fatigue resistance had a direct relationship with hardness, tensile strength and equiaxed $\alpha$ volume fraction and an inverse relationship with elongation, colony size, $\beta$ and primary $\alpha$ thicknesses. Everaerts et al. [9] found that fatigue life decreases with increasing grain size of $\alpha$ phase. Schmidt et al. [10] indicated clearly that duplex aging leads to a significant improvement of fatigue limit of highly $\beta$-stabilized titanium alloy due to a homogeneous dense distribution of acicular $\alpha$ precipitated. Generally, fatigue strength depends on microstructure parameters such as grain size of the primary $\alpha$ in bimodal microstructures, $\alpha$ grain size in equiaxed microstructures, and lamellar $\alpha$ width in lamellar microstructures [7] [8].

\section{Experimental Work}

In this work, TC21 samples were received as bars with $7 \mathrm{~mm}$ diameter and 140 $\mathrm{mm}$ length. The $\beta$ transus temperature was previously determined and it was found at $960^{\circ} \mathrm{C}$ [11]. The chemical composition of the investigated TC21 alloy is given in Table 1.

Two heat treatment cycles were applied on the as-received TC21 Ti-alloy. The first cycle was called single stage heat treatment (SSHT), which involved solution treated at $900^{\circ} \mathrm{C}$ for $15 \mathrm{~min}$ followed by cooling using air cooling (AC). Consequently, aging treatment was applied at $575^{\circ} \mathrm{C}$ for $4 \mathrm{hr}$. The other cycle was called duplex stage heat treatment (DSHT), that involved solution treated at $900^{\circ} \mathrm{C}$ for $15 \mathrm{~min}$ then furnace cooling to $800^{\circ} \mathrm{C}$ with a cooling rate of $1^{\circ} \mathrm{C} / \mathrm{min}$ and holding for $20 \mathrm{~min}$, thereafter the samples cooled down to room temperature using air cooling (AC). Consequently, aging treatment was also applied at $575^{\circ} \mathrm{C}$ for $4 \mathrm{hr}$. The samples for optical metallographic examination were prepared by mechanical polishing and then etching with a solution consisting of $3 \%$ $\mathrm{HF}, 30 \% \mathrm{HNO}_{3}$ and $67 \% \mathrm{H}_{2} \mathrm{O}$. Hardness was carried out using Vickers hardness 
Table 1. Chemical composition of the as-received TC21 Ti-alloy (mass fraction, \%).

\begin{tabular}{ccccccccccccc}
\hline $\mathrm{Al}$ & $\mathrm{Mo}$ & $\mathrm{Nb}$ & $\mathrm{Sn}$ & $\mathrm{Zr}$ & $\mathrm{Cr}$ & $\mathrm{Si}$ & $\mathrm{Fe}$ & $\mathrm{C}$ & $\mathrm{N}$ & $\mathrm{H}$ & $\mathrm{O}$ & $\mathrm{Ti}$ \\
\hline 6.5 & 3.0 & 1.9 & 2.2 & 2.2 & 1.5 & 0.09 & 0.05 & 0.01 & 0.01 & 0.001 & 0.07 & Bal. \\
\hline
\end{tabular}

with a load of $196 \mathrm{~N}(20 \mathrm{~kg}$ ) for $15 \mathrm{~s}$. Round samples with a gage length and diameter of 20 and $4 \mathrm{~mm}$, respectively, were machined for tensile testing according to ASTM E8-16 standard at room temperature using a strain rate of 0.5 $\mathrm{mm} / \mathrm{min}$.

The fatigue test was carried out using rotary bending fatigue testing machine at room temperature. The samples were subjected to alternate cycles of tensile and compressive stresses using a stress ratio of $R=-1$. The speed of the test machine ranged from 500 to 5000 cycles per minute. The optimum speed chosen for these tests was 3000 cycles per minute. The tests were completed for a range of ten stress levels of $85 \%, 80 \%, 77.5 \%, 75 \%, 72.5 \%, 70 \%, 67.5 \%, 65 \%, 60 \%$ and $57.5 \%$ of the ultimate tensile strength (UTS) value to plot a simple S-N curve. The configuration of the fatigue samples is shown in Figure 1. The fractography of some selected samples was analyzed and studied using field emission scanning electron microscope (FESEM).

\section{Results and Discussion}

\subsection{Microstructure Evaluation}

\subsubsection{As-Received Condition}

Figure 2 shows the microstructure of the as-received TC21 samples that composed of equiaxed $\alpha$ phase (black color) and $\beta$ phase (white color). The average grain size of $\alpha$ phase was in the range of $2.5 \mu \mathrm{m}$ and its volume fraction approached 65\%. The equiaxed $\alpha$ phase is distributed homogeneously in the entire field of view.

\subsubsection{Solution Treated Condition}

The typical microstructure of SSHT \& DSHT samples showed an equiaxed shape of primary $\alpha$ phase $\left(\alpha_{\mathrm{p}}\right)$ that distributed homogenously in the $\beta$ phase, Figure 3 . For SSHT, secondary $\alpha$ phase $\left(\alpha_{\mathrm{s}}\right)$ was precipitated in the residual $\beta$ phase due to the low cooling rate using air cooling and aging treatment. On the other hand, DSHT, $\alpha_{\mathrm{s}}$ was precipitated in the residual $\beta$ phase due to step cooling in furnace and also low cooling rate using air cooling as well as aging treatment. As shown in Figure 3, the morphology of $\alpha$ and $\beta$ phases do not change with changing the solution treatment, while their volume fraction and grain size were changed. The volume fractions of $\alpha_{\mathrm{p}}$ and $\alpha_{\mathrm{s}}$ phases were determined for the different heat treatment parameters. Volume fractions of $\alpha_{\mathrm{p}}$ and $\alpha_{\mathrm{s}}$ for SSHT were approximately $45 \%$ and $13 \%$, respectively. On the other side, for DSHT the volume fractions of $\alpha_{\mathrm{p}}$ and $\alpha_{\mathrm{s}}$ were about $41 \%$ and $10 \%$, respectively. The different stage solution treatments have significantly effect on the grain size of $\alpha_{\mathrm{p}}$ phase. For SSHT, grain size of $\alpha_{\mathrm{p}}$ phase was in the range of $2.1 \mu \mathrm{m}$ and increased to $3.15 \mu \mathrm{m}$ in case of DSHT. 


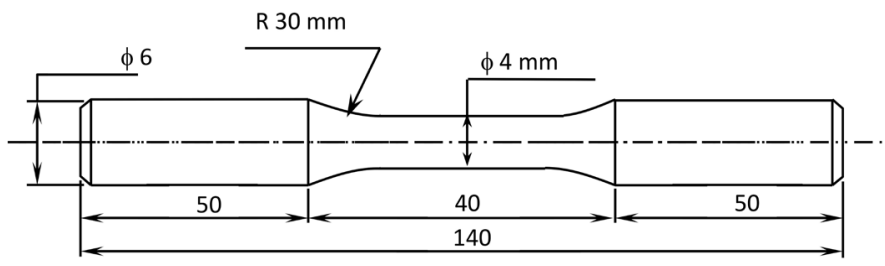

Figure 1. Schematic drawing the dimensions of the fatigue sample.

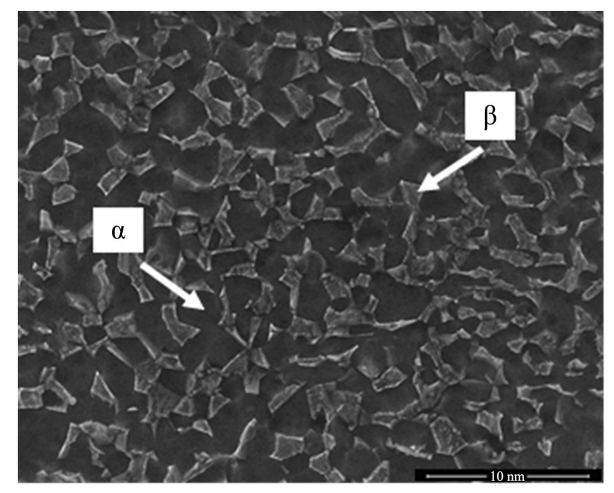

Figure 2. FESEM micrograph of as-received TC21-Ti alloy.
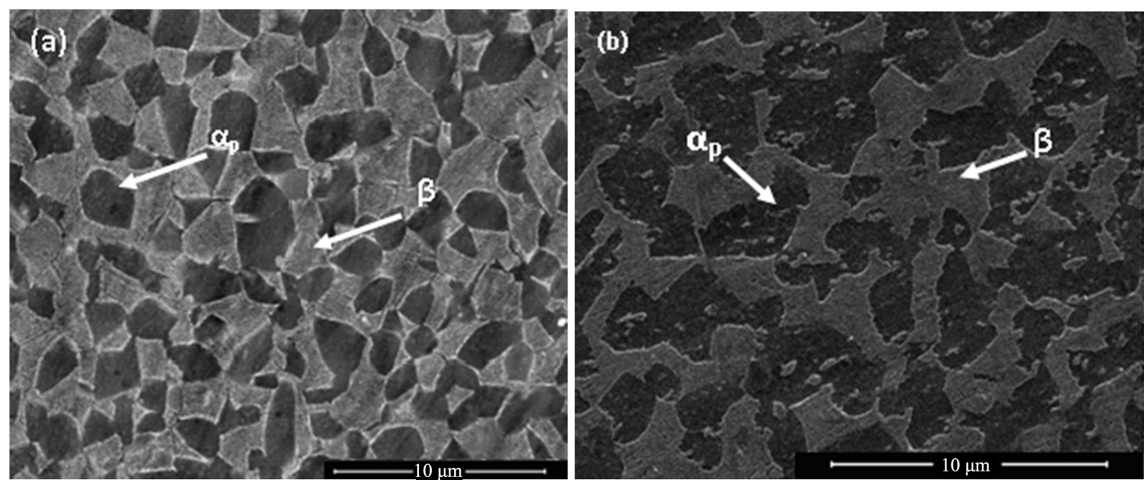

Figure 3. FESEM images for different stages: (a) SSHT and (b) DSHT.

Fine secondary $\alpha$ platelets $\left(\alpha_{\mathrm{s}}\right)$ were precipitated from the supersaturated $\beta$ phase during solution treatment and aging, Figure 4. These precipitated $\alpha_{s}$ platelets are thought to be the main reason for strengthening the studied TC21 Ti-alloy [12]. This is because $\alpha_{s}$ platelets will enhance the $\alpha / \beta$ inter phase boundary. Fine secondary $\alpha$ platelets together with residual $\beta$ phase are called "residual $\beta$ matrix strengthened by fine secondary $\alpha$ platelets" ("residual $\beta$ matrix" for short). This result agrees with the study reported by Wang et al. [13].

\subsection{Tensile and Hardness Properties}

Hardness and tensile properties of SSHT \& DSHT are given in Table 2. SSHT samples exhibited higher hardness, yield strength (YS) and ultimate strength (UTS) compared to DSHT samples due to existing of high percentage of the residual $\beta$ phase and secondary $\alpha$ phase $\left(\alpha_{\mathrm{s}}\right)$. In contrast, DSHT have higher elongation (El) and reduction of area (RA). 


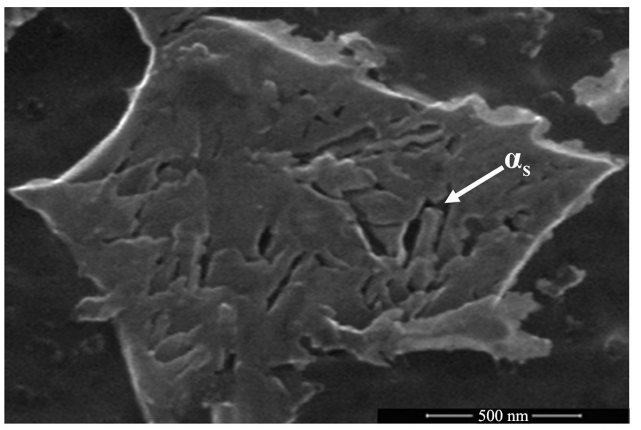

Figure 4. Fine secondary a platelets in the residual $\beta$ phase.

Table 2. Tensile and hardness properties with two heat treatment cycles.

\begin{tabular}{cccccc}
\hline Cycle & Hardness, $\mathrm{HV}_{20}$ & $\begin{array}{c}\text { Yield strength YS } \\
(\mathrm{MPa})\end{array}$ & $\begin{array}{c}\text { Ultimate tensile strength UTS } \\
(\mathrm{MPa})\end{array}$ & $\begin{array}{c}\text { Elongation El (\%) } \\
\text { Reduction in area RA } \\
(\%)\end{array}$ & $\begin{array}{c}\text { (\%) } \\
\text { SSHT }\end{array}$ \\
DSHT & 305 & 1297 & 1336 & 11 & 26 \\
\hline
\end{tabular}

\subsection{Fatigue Properties}

Figure 5 shows S-N curves for both single and duplex stage heat treatments. In SSHT, all samples failed at ultimate strength levels from $85 \%$ to $67.5 \%$. However, at $65 \%$ to $57.5 \%$ the samples did not fail. In DSHT, the samples failed at all ultimate strength levels from $85 \%$ to $65 \%$. However, when tested at $60 \%$ and $57.5 \%$ the samples did not fail. SSHT showed the highest fatigue strength of $868 \mathrm{MPa}$. For DSHT was reported at $743 \mathrm{MPa}$. The fatigue strength at 107 cycles for Ti-6Al-4V ranges from $620-725 \mathrm{MPa}$ [14]. This means that TC21 alloy has fatigue strength higher than the widely used conventional titanium alloy Ti6Al4V, with the same structure of $(\alpha+\beta)$.

Since fatigue performance cannot be analyzed without considering microstructure evolutions, hardness and tensile test results. Then, fatigue data must be interpreted based on these properties. Consequently, enhancing in fatigue strength in case of SSHT was due to high strength, hardness and existing of high percentages of residual $\beta$ phase and $\alpha_{\mathrm{p}}$ phase in the microstructure. Other reason for increasing the fatigue of SSHT in comparison with DSHT was the presence of high amount of precipitated secondary $\alpha$ phase in the residual $\beta$ phase with reduced $\alpha$ grain size in equiaxed structures that acting like barriers against fatigue crack propagation. This result was proved in previous studies [7] [8]. The more $\alpha_{\mathrm{p}}$ volume fraction with less grain size, the better high fatigue performance is achieved. Considering tensile properties have direct relationship with fatigue strength. It can be concluded here that optimizing the fatigue performance of the studied TC21 Ti-alloy can be achieved by controlling the microstructure features such as volume fraction and grain size of $\alpha_{\mathrm{p}}$ phase.

\subsection{Fatigue Fractography}

The fracture surface of single and duplex stage heat treatments was examined by FESEM (Figure 6). As it is observed in SSHT, Figure 6(a), there are some big 


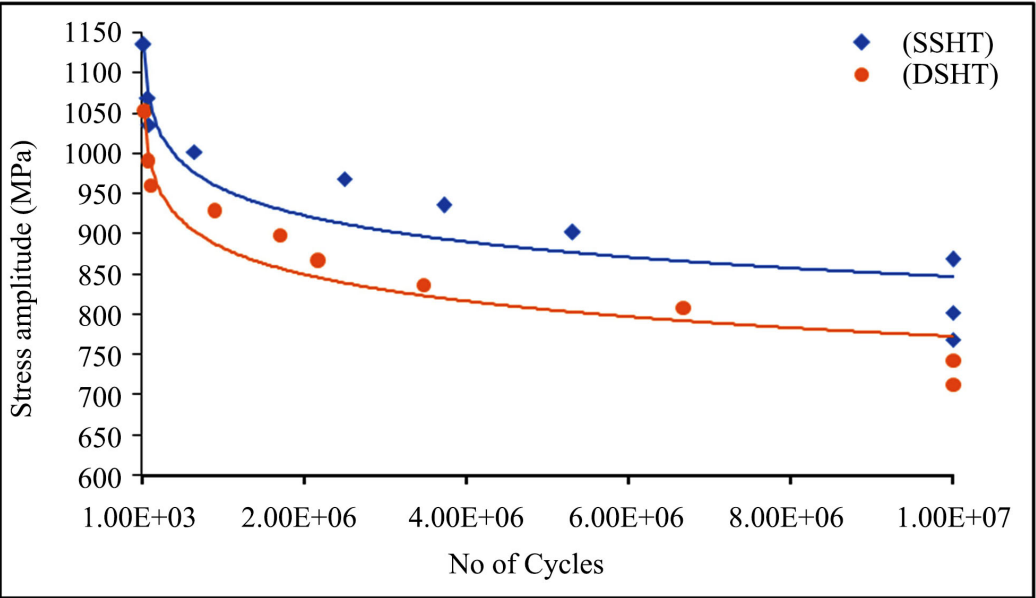

Figure 5. S-N curves for SSHT \& DSHT. An arrow indicates a run out (the sample did not fail).
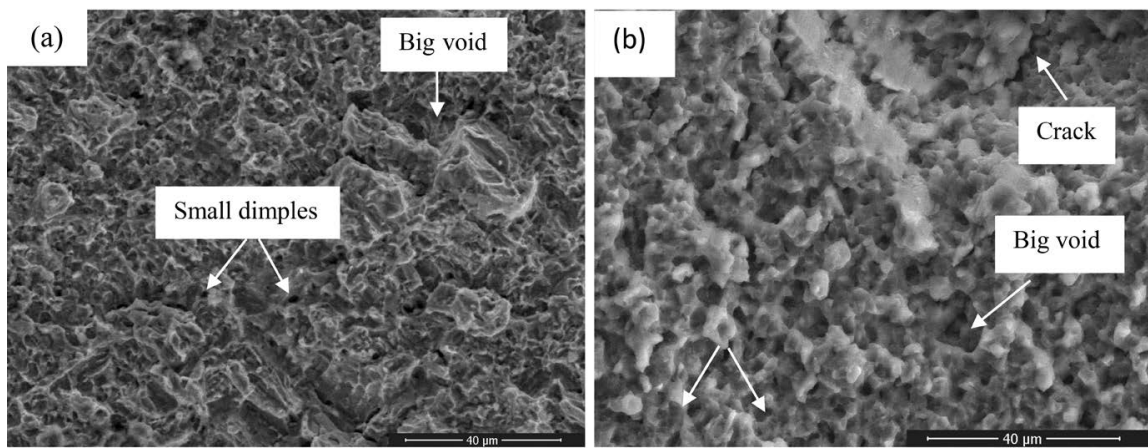

Figure 6. Fracture surface of SSHT \& DSHT samples: Central part of the surface.

voids with small dimples in fracture surface which considered as a sign of a relatively cleavage ductile fracture mode. It seems that crack nucleation has taken place at $\alpha-\beta$ interfaces and in equiaxed $\alpha$ phase. As shown in Figure 6(b), DSHT, the big and deep voids with large dimples existing in the fracture surface indicated to cleavage ductile fracture mode.

\section{Conclusions}

1) For SSHT, secondary $\alpha$ phase $\left(\alpha_{\mathrm{s}}\right)$ was precipitated in residual $\beta$ phase due to low cooling rate using air cooling and aging treatment. For DSHT, $\alpha_{\mathrm{s}}$ was precipitated in the residual $\beta$ phase due to step cooling and low cooling rate using air cooling as well as aging treatment.

2) Morphology of $\alpha$ and $\beta$ phases does not change after solution treatment with two different stages and aging treatment, while their volume fraction and grain size were changed.

3) The highest fatigue strength of $868 \mathrm{MPa}$ was obtained for SSHT samples and DSHT samples were reported low fatigue strength of $743 \mathrm{MPa}$.

4) Fractography of fatigue surfaces indicated cleavage ductile fracture mode for both heat treatment cycles. 


\section{Conflicts of Interest}

The authors declare no conflicts of interest regarding the publication of this paper.

\section{References}

[1] Lütjering, G. and Williams, J.C. (2007) Titanium. 2nd Edition, Springer, Berlin Heidelberg, New York.

[2] Banerjee, D. and Williams, J.C. (2013) Perspectives on Titanium Science and Technology. Acta Materialia, 61, 844-879.

https://doi.org/10.1016/j.actamat.2012.10.043

[3] Ibrahim, K.M., EL-Hakeem, A.M. and Elshaer, R.N. (2013) Microstructure and Mechanical Properties of Cast and Heat Treated Ti-6.55Al-3.41Mo-1.77Zr Alloy. Transactions of Nonferrous Metals Society of China, 23, 3517-3524. https://doi.org/10.1016/S1003-6326(13)62896-4

[4] Lia, G., Xia, F., Gao, Y. and He, Y. (2016) Microstructure Control Techniques in Primary Hot Working of Titanium Alloy Bars: A review. Chinese Journal of Aeronautics, 29, 30-40. https://doi.org/10.1016/j.cja.2015.07.011

[5] Tang, B., Kou, H.-C., Wang, Y.-H., Zhu, Z.-S., Zhang, F.-S. and Li, J.-S. (2012) Kinetics of Orthorhombic Martensite Decomposition in TC21 Alloy under Isothermal Conditions. Journal of Materials science, 47, 521-529. https://doi.org/10.1007/s10853-011-5829-5

[6] Wang, Y.-H., Kou, H.-C., Chang, H., Zhu, Z.-S., Zhang, F.-S., Li, J.-S. and Zhou, L. (2009) Influence of Solution Temperature on Phase Transformation of TC21 Alloy. Materials Science and Engineering: A, 508, 76-82. https://doi.org/10.1016/j.msea.2008.12.019

[7] Wu, G.-Q., Shi, C.-L., Sha, W., Sha, A.-X. and Jiang, H.-R. (2013) Effect of Microstructure on the Fatigue Properties of Ti-6Al-4V Titanium Alloys. Materials and Design, 46, 668-674. https://doi.org/10.1016/j.matdes.2012.10.059

[8] Davari, N., Rostami, A. and Abbasi, S.M. (2017) Effects of Annealing Temperature and Quenching Medium on Microstructure, Mechanical Properties as Well as Fatigue Behavior of Ti-6Al-4V Alloy. Materials Science \& Engineering. A, 683, 1-8. https://doi.org/10.1016/j.msea.2016.11.095

[9] Everaerts, J., Verlinden, B. and Wevers, M. (2016) The Influence of the Alpha Grain Size on Internal Fatigue Crack Initiation in Drawn Ti-6Al-4V Wires. Procedia Structural Integrity, 2, 1055-1062. https://doi.org/10.1016/j.prostr.2016.06.135

[10] Schmidt, P., El-Chaikh, A. and Christ, H.-J. (2011) Effect of Duplex Aging on the Initiation and Propagation of Fatigue Cracks in the Solute-Rich Metastable $\beta$ Titanium Alloy Ti 38-644. Metallurgical and Materials Transactions A, 42, 2652-2667. https://doi.org/10.1007/s11661-011-0662-7

[11] Elshaer, R.N., Ibrahim, K.M., Barakat, A.F. and Abbas, R.R. (2017) Effect of Duplex Heat Treatment on Tribological Behavior of TC21 Titanium Alloy. Journal of Metallurgical Engineering (ME), 6, 1-15.

[12] Shao, H., Zhao, Y.-Q., Ge, P. and Zeng, W.-D. (2013) Crack Initiation and Mechanical Properties of TC21 Titanium Alloy with Equiaxed Microstructure. Materials Science \& Engineering: A, 586, 215-222. https://doi.org/10.1016/j.msea.2013.08.012

[13] Wang, K. and Li, M.-Q. (2014) Effects of Heat Treatment and Hot Deformation on 
the Secondary $\alpha$ Phase Evolution of TC8 Titanium Alloy. Materials Science \& Engineering: $A, 613,209-216$. https://doi.org/10.1016/j.msea.2014.06.056

[14] Wood, E.T. (2015) Thermal Processing and Mechanical Properties of Beta Phase Titanium Alloys for Biomedical Applications. Master of Science in Metallurgical Engineering, Montana University, Missoula, Montana. 